\title{
The Impact of Web Portal in Library and Information Services in the $21^{\text {st }}$ Century
}

\author{
Ahmed Tijjani Abdul \\ College Library, Federal College of Education, Zaria-Nigeria
}

\section{Doi:10.5901/jesr.2013.v3n10p37}

\begin{abstract}
The advent of website which is also referred to as "web portal" is one of the greatest revolution in the world of providing and promoting library and information resources and services. Today, accessibility to information and information retrieval as a result of websites as helped libraries and information centers to effectively render quality library services to their customers. Web portal has great advantages in information generation, processing and accessibility to information on demand. Users have the advantage of visiting websites to obtain readily available information via internet. Therefore, this paper attempt to discuss the concept of web portal as an emerging technology that could help to facilitate the storing and retrieval of information and its services particularly as it affect the modern flow and management of information in the 21st century. The concepts of library service were also highlighted as that phase of library work that assists library users with relevant information through the use of library resources. The applications of the technology within Nigeria context were discussed as well as factors that could pose are posing threat to its management in library services to library users. Finally, recommendations were proffered as solutions for the use of web technology within the context of library and information services.
\end{abstract}

Keywords: Web Portal, Library Services.

\section{Introduction}

As digital resources increased exponentially over the last decade, academic libraries have heavily invested in electronic books, research databases, as well as electronic journals, and made them accessible via their library Web portals. Some libraries also undertake usability initiatives to improve their Web portals in order to provide users with better and easier access to their electronic collections and services. In the late 1990s, the web portal was a hot commodity. After the proliferation of web browser in the late 1990s, many companies tried to build or acquire a portal to have a piece of the internet market. The web portal gained a special attention because it was for many users, the starting point of their web browser. The World Wide Web continues to be the preeminent application on the internet because it has regularly reinvented itself. Infact, for most people, the World Wide Web has become synonymous with the internet. These changes may prove to be more far- reaching than any other change to hit the web. Portals are not pad or a new name for something that we've been doing all along; they serve as a repository information centre for dynamic and potential users who subscribe to their site. Portal virtually gives every users a customized, personalize and unique web page. Every information technology (I.T) vendor and many I.T professionals are rushing to produce portal ware and portal- like web pages without fully understanding the scope of a portal undertaking for an institution or even really understanding what a web portal is or should do. With recent development, many library and information centers have been modernized to meet the need of the global change. The traditional practices of librarianship are fast adapting to the new age technologies for better service delivery to library 
users.

\section{The Concept of Web Portal}

According to Howard (2007) web portal is a web site that brings together information from diverse sources in a unified way. Usually, each information source gets its dedicated area on the page for displaying information. Web portals offer services such as e-mail, news, stock prices, information, data bases and entertainment. According to Osuala (2006) Opines that web portal is computer files, encoded using Hypertext Mark- up Language (HTML) and containing text, graphics and sound files that is accessible through the World Wide We According to Duncan (2010) defined web portal as compendium of knowledge which exposes library customers to varieties of information on subject disciplines which they need as tools for study and research purpose. Macdonald (2009) Submitted that web portal is in contestable and indispensable in information management. While Okon (2005) define web portal as a designed site where users can easily go from one page to another navigating the information of their choices. He further explain that, web portal have the information stored into links to various topics such as news, business, sports, entertainment, finance, travel and much more. Yahoos, Google, AOL are popular portals on the internet.

Spenser (2009) further described web portal as a site that allow global computers net work called the internet to display multi media document such as text, photographs, illustrations, video, music or computer programs. They also often include links to other site in the form of hyper text, highlighted or colour text that the users can click on with their mouse, instructing their computer to jump to the site. Richard (2008) opined that web portal is divided and categorized into three; namely:-

1. Personalized web portal

2. Customized web portal

3. Corporate web portal

The above were further classified into two groups. Vertical Enterprises Portals (VEPs), and Horizontal Enterprises Portals (HEPs), also called mega portal.

Horizontal Enterprises portal is a public web site that attempt to provide its users with all the services they might need. Such as net centre and my excite. All HEPs includes shopping, weather, stock prices, news, search engines, chat groups horoscopes and so forth, and they all urge you to make their page the first page you see when you use the web. They allow you to personalize the page you see by selecting the cities for which you would like the weather, choosing the stocks and news sources you'd like to display. Some HEPs lets you do extensive personalization, allowing you to build multiple stock portfolios and see frequently updated valuations. Typically, but not always, the personalization is held in web cookies that are stored on local computer. Accessing a HEPs from another computer loses all your personalization. HEP always include advertising that pays for the portal and their goal is to attract as many eyes balls as possible. HEPs do not allow academic or corporate employees access to every thing they really need on the web. Much of what an employee needs on the web is specific to where he or she works and his or her role in that organization, for example, if an employee working in the department of a university could only have access to information that concern his or her department and related to his or her job in the university because it has been codified and personalized. On the other hand if an employee is in need of information outside the scope of his department and roles, he or she would have to restore to the use of Vertical Enterprises Portals(VEPs).

Vertical Enterprises Portals (VEP) is a portal that delivers organization- specific information in a user-centric way. Whereas HEPs looks the same to all who first enter it, VEPs looks quite different. Unlike HEPS, VEPs require authentication for access. When a user logs on to VEPs, it produces a customized portal page, tailored to the user who logged on. It knows a great deal about the user who logged on because the user is a member of the organization that produced the VEPS. A customized web portal is done by the portal soft wares knowledge of an authenticated 
portal user, when you authenticate to a vertical portal, it can gain access to a great deal of information about you and present you with a customized portal page. The portal customization engine that resides on the portals application server is responsible for determining each user's roles, responsibilities, work flow, and the information that the person is authorize to access. HEPs have little or no customization, since the initially have access to very little information about you. A VEP is a single page with access to all the information and the applications a user commonly needs. It will contain alert, navigation tabs and icons, directories, graphics and links.

\section{Concept of Library Services}

James (2008) defined library services as varied activities that is rendered to library users for effective and efficient patronage and given the required information for research work. Akintunde (2004) opines that, library services in many tertiary institutions have either earned the institution accreditation or failed them in the provision of effective and efficient services for academic excellence. In another development, Mohammed(2011) in his lectures delivered to undergraduate students on security and preservation of library resources said that, library services are categorized into two namely, solicited and unsolicited library services. Solicited library services are those services that are mandatory and compulsory for any library to provide for its users. Services such as reference services, bibliographic services, current awareness services, reader services, information services, bindery services, indexing and abstracting services, document delivery services, inter library loan services, internet services, lending services, online public access catalogue(OPAC), photocopying services, research advisory services, referrer services.etc. Unsolicited library services are those services that are not mandatory and compulsory for library to provide for its user but it add more value to the mandatory library services. These services are as follows:- Book talk, Display and Exhibition, TV show and radio services, Teleconferencing, Extension services such as film show, puppet shows, picture book time, story telling etc.

\section{Library and Information Application in the age of Science and Technology}

It has become pertinent and necessary for library and librarian to move from the traditional way of acquiring, processing, storing and dissemination of information to a modern way through the use of computers and communication technologies. More so, that users' are no longer coming to the library to obtain and acquire relevant information in text using various text books, journals, and magazines. They prefer to use their computers, phones, other storage facilities in their domain without covering much distance to get their needed information.

The adoption and use of these technologies made library and information centers to be recognized as information scientist because they adapt to any changes so as to pursue effective and efficient service delivery to their patrons or customers. The integration and adoption of this technology into library services has not only improved library services, but also added more value to the profession of library and information science. Web portal was adopted to complement and supplement the traditional way to a modern conducive and stressless way of obtaining information.

Williams (2009) opined that, the introduction of web portal into library has greatly enhanced the efficiency and effectiveness of library services. Client can get satisfactory answer to their queries within the shortest time. Librarian can perform their services more efficiently. Among the greatest benefit of internet to library services is the inexpensive way to communicate with other internet users world wide. It is used to obtain important resources for teaching and learning in schools. It is possible to send out orders to publishers and producers of teaching and learning materials and equipment.

Thompson (2011) submitted that, services such as ordering and processing of library materials are made easier through internet. Libraries using appropriate commercial databases can locate selected materials and send out e-mail orders to publishers. Reference services and 
resources are moving away from its conventional book formant to electronic format. When there is a need, information obtained can be printed. Students, teachers and other researcher can look up items of interest in electronic encyclopedias. Articles on particular subjects from a variety of publication could be called without having to buy the publication. Services offered by the internet is the World Wide Web using a technique that will underline or highlight a word, a phrase or an image in the document. The highlighted word or image is a clue to the user. The document can be fetched and displayed immediately for the reader irrespective of its location. It links you to the actual documents, not just the reference to them. The web also support the storage and retrieval or playing of photographs, graphics, animations.etc. This service greatly helps the library in disseminating information to library users

\section{Benefit of Web Portal to Library Services}

The adoption and integration of web portal into library services has changed and improved the phase of providing or making information available to users and these are:-

1. It has improved speed limitation in searching and retrieving information.

2. It has encouraged resource sharing among two or more libraries.

3. It has added more value to information professional.

4. It has increase users patronage with the view of accessing library collections.

5. It has enable sending and receiving of information within a short period of time.

6. It has made ordering and processing of library materials easier.

In a related development (2008) identified the benefit of web portal as follows:

1. Web Portal provides information on all subject discipline

2. Web Portal address saves time in searching and retrieving information

3. Web Portal exposes users to many researches

4. Web Portal provide addresses for accessibility

5. Web Portal can be connected to web cam camera for photographic information

6. Web Portal promote good information management

7. Web portal technology is highly flexible as you can search for different information at a time.

8. Once the server is "on" you can manipulate web site to your advantage.

\section{Global Implication of Web Portal in Providing Library Services}

The trends of librarianship in library and information centre require much more than the traditional way of providing and disseminating information to their customers. But looking at the implication of web portal, one will be curious in asking such questions as; will librarians and information professionals practice librarianship and still be relevant without adopting this technology; can they render services as the traditional way and still be current?. Patrick (2008) submitted that global web portal has changed the way we handle information. The world is referred to as" Global Village" therefore; web portal has created a situation of open communication and interaction among members of the community. In a related development Murray (2009) observed that web portal has nothing to do with distance barrier. People all over the world can connect to the web without problem of getting different kinds of information. Web portal exposes internet users to various kinds of web sites. Dennis (2010) agrees with Murray (2009) but stressed that web portal should present its information comprehensively and well organize. The web site should give details of how to access web site and get relevant information for career development.

Today, many libraries have come into lime light because of the adoption and application of new technology in providing library service. The implication means that no printed books or other printed materials of any kind will be use in the library, no one including the staff will be allow to bring any of those materials into the library, information will be available only in digital format and 
accessible only electronically. The library will have no photocopying machines, no computer printers, and no provision for the receipt of mail and no waste baskets and recycling bins. Neither staff nor users will be allowed to bring note books or any other form of paper into the library. Only personal data assistance, computer and other paper- free electronic devices may be used to bring information into, or, take information out of the library or information centers.

\section{Application of the Technology within Nigeria Context}

In context to Nigeria as a developing country, web portal has been accommodated, adopted, in most academic institution (both private and public), companies, hospitals, and government agencies, but the syndrome of maintenance culture, funding is inadequate, staff are not qualified to operate the equipment, the problem of obsoleteness' is causing more harm than good. Most web portals are designed for commercial purposes so as to inform their customers on latest development as regards to goods and services. It is also used in transacting business such as buying and selling of products. Nigeria as nation is also faced with the problem of insufficient power supply and problem of connectivities thereby putting the customers at disadvantage than advantage. For Nigeria to adapt to this technology, training retraining of information professional need to be made so as to meet the main stream of digital revolution because library services today require more global networking in delivery effective and efficient services.

\section{Challenges of Web Portal in the Provision of Library Services}

In as much as web portal initiative is good; there are observed obstacle that can render library services ineffective and disappointing among which are;

1. Problem of dialoging among librarians for improve library services

2. Problem of enacting a policy mandating libraries to adopt web portal in providing library services to customers.

3. Problem of qualified staff in the management of information resources using Web Portal technology.

4. The problem of interrupted power supply particularly in Nigeria

5. Problem of maintenance culture as web portal require good maintenance for sustainability and development.

6. Web Portal can be affected by bandwidth as the bigger the bandwidth the wider the area network.

7. Web Portal is expensive to manage as it requires constant activation from time to time.

8. Problem of constant power supply to operate the technology without interruption.

\section{Conclusion}

In Africa and, particularly, Nigeria, adoption and adaption of web portal is the case; Nonetheless, significant progress will have to be made for Nigerians libraries to be in the main stream of the digital revolution. Library services require more global networking in delivering service. Cost of technological infrastructure and services, dwindling financial resources, all contribute to inefficiency of staff and the technology to function properly even when they are made available for effective library services, electricity (power supply) is another problematic phenomenon, therefore rendering library inefficiency in the $21^{\text {st }}$ century. Librarians and other information professional needs to complement and support each other for a meaningful and functional development.

\section{Recommendations}

The following recommendations were drawn for effective and efficient library services in the $21^{\text {st }}$ 
century as regard the adoption and adaptation of new technology such as web portal.

1. There is a need for collective dialogue and corporation among information professionals.

2. There should be a policy mandating every library and information professional to adopt and make functional practice of web portal in making information available to their customers.

3. Training and retraining of library staff locally and internationally should be encourage in all aspect of information management and resource development using web portal.

4. Constant power supply should be maintained or making available generator set for power failure

5. Maintenance culture should be emphasize to increase the life span of the technology

6. Information professionals should be encourage to acquire big bandwidth for improve library service using web portal.

7. Funding should be made and checked judiciously for maintenance and Management of web portal.

8. Constant power supply should be maintained or making available generator set for power failure.

\section{References}

Akintunde, J. (2004) The Role of ICT, Information Management and Library Services. Ibadan: University Press.

Dale, T (2008) Web Portal, Library Services and Information Management. Michigan: University of Michigan Press. Pg 32.

Dennis, W (2010) Websites and Web Portal Management. Cambridge: Macmillan Press Ltd. Pg 53.

Dunca, J. (2010) The role of web portal in Information Management. New York: Clive Bingley Press Itd, Howard, S. (2007) Information compendium using ICT Facilities.- New York: Mc-Graw Hall Book.

James, B (2008) Library customers perception about ICT.- New York: Clive Bingly Press. P. 78.

Macdonald, P, (2009) Management of web portal and promoting information management. Cambridge: University of Cambridge Press Itd.

Mohammed, Z. (2011) Preservation and Security of Library Materials. Zaria: Ahmadu Bello University Press.

Murray, D (2009) An Introduction to Web Portal and Management of Library Resources. London: Oxford University Press. Pg 38.

Okon, K. (2005) ICT Application in Academic Institution: Challenges and Prospect. Ibadan: University Press.

Patrick, J. C. (2008) An Approach to Web Portal and Information Management. New York: Clive Bingly Press. Pg. 102.

Richard, N. K. (2008) Web Portal and Higher Education: Technologies to make IT Personnel. New York: Clive Bingley Press.

Spenser, M (2009) Information Technology in Africa: Challenges and Prospects: Nairobi: ACTS Press.

Thompson, H. (2010) Promoting current awareness services through internet. London: H.W.Wilson press, P.88.

Williams, P (2009) An introduction to the use of internet in academic libraries. London: Oxford University Press. P. 36. 